\title{
Fontes de título no repertório tipográfico das oficinas de Jorge Seckler entre 1878 e 1890
}

\author{
Display typefaces in Jorge Seckler letterpress printing shops \\ typographic repertoire between 1878 and 1890
}

Luiza Midori Yoshimura, Priscila Lena Farias

memória gráfica, tipografia, século XIX, São Paulo

Com o objetivo de contribuir para os estudos sobre memória gráfica brasileira, o foco deste artigo é o repertório tipográfico das oficinas de Jorge Seckler entre 1878 e 1890. Partiu-se da catalogação, identificação e descrição das fontes de título empregadas em anúncios impressos no Almanach do Estado de São Paulo para 1890. Uma análise comparativa entre as famílias tipográficas encontradas nesta e em outras publicações do mesmo impressor (um indicador para o ano de 1878 e um almanaque para o ano de 1884) foi então realizada, para compreender e verificar a evolução e variedade deste repertório. Foi possível observar tendências no emprego de determinados estilos tipográficos, como a predominância inesperada de fontes serifadas em títulos, e a valorização da tridimensionalidade.

graphic memory, typography, 19th century, São Paulo

With the purpose of contributing to the studies on Brazilian graphic memory, this article focuses on Jorge Seckler's letterpress printing shops typographic repertoire between 1878 and 1890. We stared from the cataloging, identification and description of the display fonts used on advertisements printed in the Almanach do Estado de São Paulo para 1890. A comparative analysis of the typefaces found in this and in other publications by the same printer (an 'indicator' for 1878 and an almanac for 1884) was then conducted, in order to understand and verify the evolution and assortment of this repertoire. Tendencies in the use of certain typographic styles could be observed, such as the unexpected prevalence of serif fonts for titles, and the valorization of tridimensional shapes.

\section{Introdução}

O foco deste artigo é o repertório tipográfico de Jorge Seckler entre 1878 e 1890, com ênfase nas fontes de título (letras com maior formato, eventualmente ornamentadas). Partindo da identificação e catalogação de famílias tipográficas presentes em anúncios no Almanach do Estado de São Paulo para 1890, foi realizada uma análise comparativa dos resultados obtidos com amostras de tipos encontradas em outras publicações da mesma empresa. O intuito foi descrever e analisar esse conjunto, de forma a contribuir para a reconstrução do repertório tipográfico de Seckler, verificando sua evolução e variedade. O uso deste repertório ao longo dos anos foi também analisado, em busca de indicações sobre o gosto tipográfico oitocentista (Farias e Onoda, 2015, p.883). Tratou-se de um esforço no sentido de resgatar parte da Curitiba | Brazil | 2021 
memória gráfica paulistana, buscando narrativas mais abrangentes e justas do design gráfico (Farias, 2016).

Jorge Seckler, imigrante alemão, foi uma figura importante para o cenário paulistano da impressão no século XIX. Sua oficina, que adotou diferentes denominações ao longo do tempo (Typographia de Jorge Seckler, Typographia ao Livro Verde, Typographia a Vapor de Jorge Seckler \& C. ${ }^{a}$ ), além da empresa sucessora Companhia Industrial de S. Paulo, foram responsáveis por publicar a mais longeva série de "almanaques", ou "indicadores" comerciais, do estado de São Paulo. Essas publicações, comuns no século XIX, eram editadas e impressas no ano anterior ao seu lançamento. Compilavam desde informes e itinerários de trens até anúncios de produtos e serviços oferecidos na capital e cidades próximas. Pela variedade de fontes empregadas, poderiam funcionar também como catálogos de tipos (Oliveira e Farias, 2018). Atuando como guias impressos, os almanaques foram um primeiro impulso sistemático de difusão da cultura impressa nas diferentes camadas sociais, em contraste com o livro, que até então era um artigo de luxo (Cruz, 2013, p. 58).

A pesquisa cujos resultados são relatados neste artigo integra um projeto mais amplo, composto por diferentes braços de estudo, que tem como objetivo a melhor compreensão acerca da memória gráfica paulistana. $O$ projeto abarca estudos sobre tipografia, design gráfico e cultura de impressão paulista com o recorte temporal de 1827 a 1927, e busca mapear usuários, fornecedores de tipos, oficinas de impressão e também identificar personalidades importantes para o campo gráfico da época.

\section{Métodos e procedimentos}

A investigação sobre o repertório das oficinas de Seckler foi realizada partindo do tratamento e catalogação das fontes de título presentes em imagens digitais do Almanach do Estado de São Paulo para 1890, cujo volume físico se encontra no acervo de obras raras da Biblioteca Mário de Andrade. ${ }^{1}$

Sendo o foco da pesquisa as fontes de título, foram priorizadas as páginas com tipos de corpos grandes ou chamativos, todas da seção de "notabilidades". Foram selecionadas quarenta páginas, um pouco mais da metade das páginas fotografadas, totalizando quarenta e nove anúncios. Dessas páginas foram catalogados e identificados os tipos utilizados para compor os nomes das empresas ou produtos divulgados e os nomes dos proprietários das empresas anunciantes.

O tratamento das imagens foi feito por meio do software Adobe Photoshop, conforme o método utilizado por Oliveira e Farias (2018) e descrito no documento Protocolo Geral Tipografia Paulistana. As etapas consistiram em:

1. Tratamento de imagens, padronizando a resolução para 300 dpi em escala 1:1, corrigindo variações de luz, distorções e manchas, aumentando seu contraste e

\footnotetext{
1 Registros fotográficos realizados pela pesquisadora Marina Onoda em 2013, no âmbito de sua iniciação científica.
} 
convertendo o arquivo para o modo "Escala de cinza", obtendo assim imagens uniformes em preto e branco, com bom contraste entre figura (tipos) e fundo (papel, figura 1).

2. Coleta de caracteres a partir de linhas de texto extraídas da imagem tratada, utilizando a ferramenta "Slice".

3. Exportação e nomeação de cada caractere conforme estabelecido no Protocolo Geral.

4. Organização e sistematização dos caracteres segundo fonte e tamanho do corpo, de modo que estes pudessem ser descritos, consultados e organizados em famílias.

Figura 1: Exemplo de página do Almanach Seckler para o ano 1890, antes e depois do tratamento

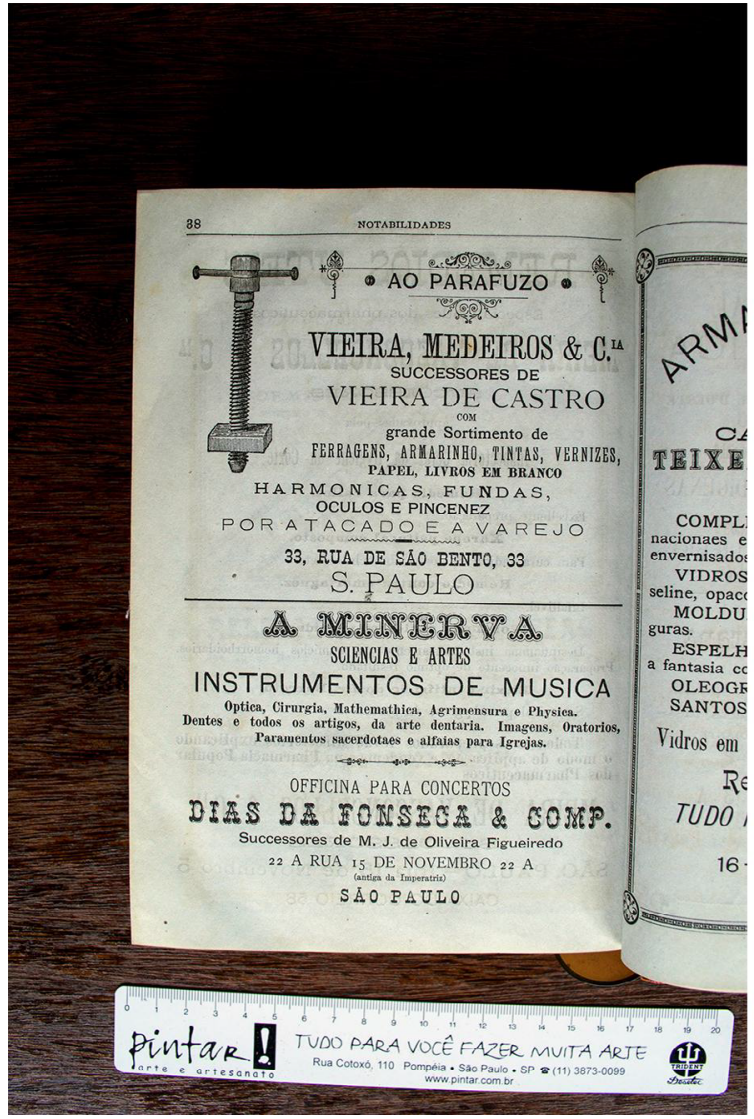

38

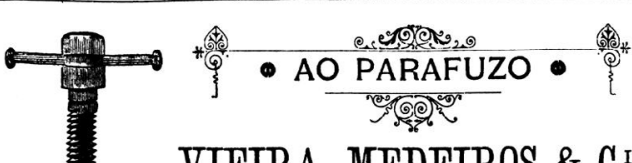

VIEIRA, MEDEIROS \& C. IA SUCCESSORES DE

VIEIRA DE CASTRO grande Sortimento de

ferragens, aRMARINHO, TINTAS, TERNIZES, PAPEL, LIVROS EM BRANCO

HARMONICAS, FUNDAS OCULOS E PINCENEZ

POR ATACADOE A VAREJO

33, RUA DE SÃO BENTO, 33

S. PAULO

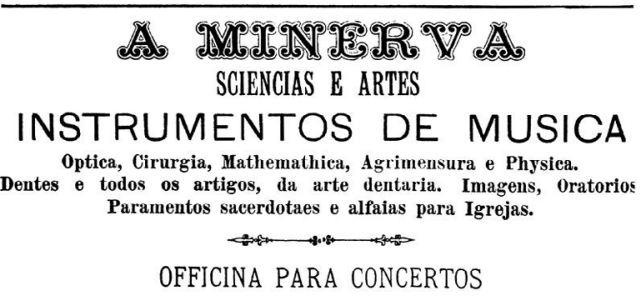

DIAS DI TOWSEE \& COMP.

Successores de M. J. de Oliveira Figueiredo 22 A RUA 15 DE NOVEMBRO 22 A SA O P P U U I O

Após o tratamento e coleta das amostras, exemplares das famílias encontradas na edição para o ano 1890 foram comparadas com amostras encontradas pela pesquisadora Heloísa Oliveira no Indicador de S. Paulo - Administrativo, Judicial, Industrial, Profissional e Commercial para o ano de 1878 e no Almanach Administrativo, Commercial e Industrial da Provincia de São Paulo para o anno bissexto de 1884 (Oliveira e Farias 2018), e com os dados sobre tipos toscanos no repertório de Seckler entre 1883 e 1895 levantados por Marina Onoda e Priscila Farias (Farias e Onoda 2015, Farias e Cunha Lima 2017). 


\section{Resultados}

Foram identificadas no Almanach Seckler para o ano 1890, 37 famílias tipográficas e 100 tamanhos de corpo distintos. Dessas famílias, três foram encontradas também no Indicador para o ano de 1878; seis tanto no Indicador (1878) quanto no Almanach para 1884; e nove nos dois Almanachs (1884 e 1890). As tabelas 1, 2, 3, 4 e 5 apresentam as famílias encontradas e sua eventual ocorrência (indicada por pontos) em publicações anteriores.

Tabela 1: Tipos escriturais encontrados no apenas no Almanach Seckler para 1890 e tipos escriturais encontrados em publicações anteriores

Apenas no Almanach

Seckler para 1890
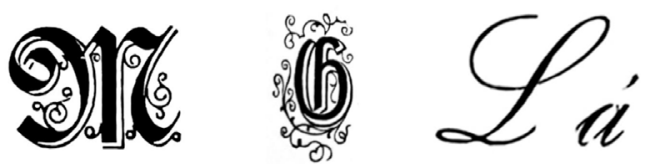

Indicador (1878) e

Almanach Secker (1884)

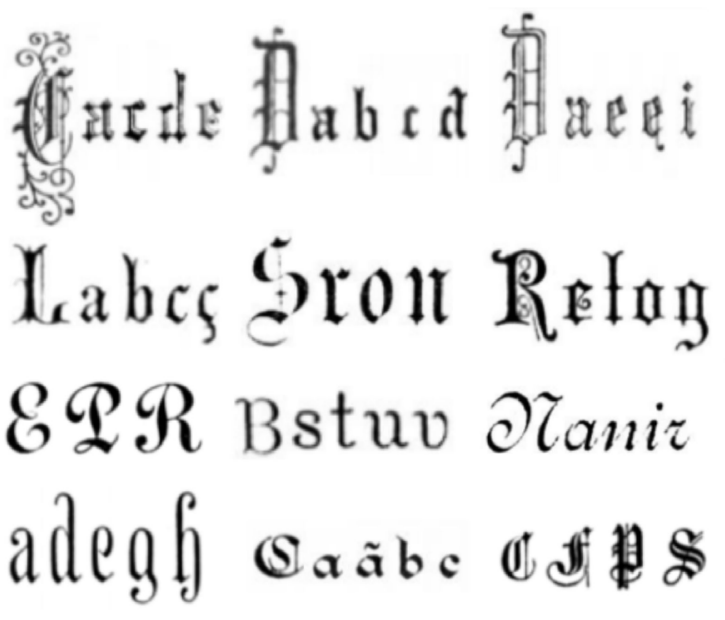

Tabela 2: Tipos grotescos encontrados no Almanach Seckler para 1890 e sua ocorrência em publicações anteriores

\begin{tabular}{lcc}
\hline Almanach (1890) & Indicador (1878) & Almanach (1884) \\
\hline & $\bullet$ & $\bullet$ \\
& & \\
\hline
\end{tabular}


Tabela 3: Tipos toscanos encontrados no Almanach Seckler para 1890 e sua ocorrência em publicações anteriores

\begin{tabular}{lccccc}
\hline Almanach (1890) & $\begin{array}{l}\text { Indicador } \\
(1878)\end{array}$ & $\begin{array}{l}\text { Almanach } \\
(1884)\end{array}$ & $\begin{array}{l}\text { Almanach } \\
(1885)\end{array}$ & $\begin{array}{l}\text { Almanach } \\
(1887)\end{array}$ & $\begin{array}{l}\text { Almanach } \\
(1888)\end{array}$ \\
\hline & $\bullet$ & $\bullet$ & $\bullet$ & $\bullet$ & $\bullet$ \\
& $\bullet$ & $\bullet$ & $\bullet$ & $\bullet$ \\
\hline
\end{tabular}

Tabela 4: Tipos fantasia encontrados no Almanach Seckler para 1890 e sua ocorrência em publicações anteriores

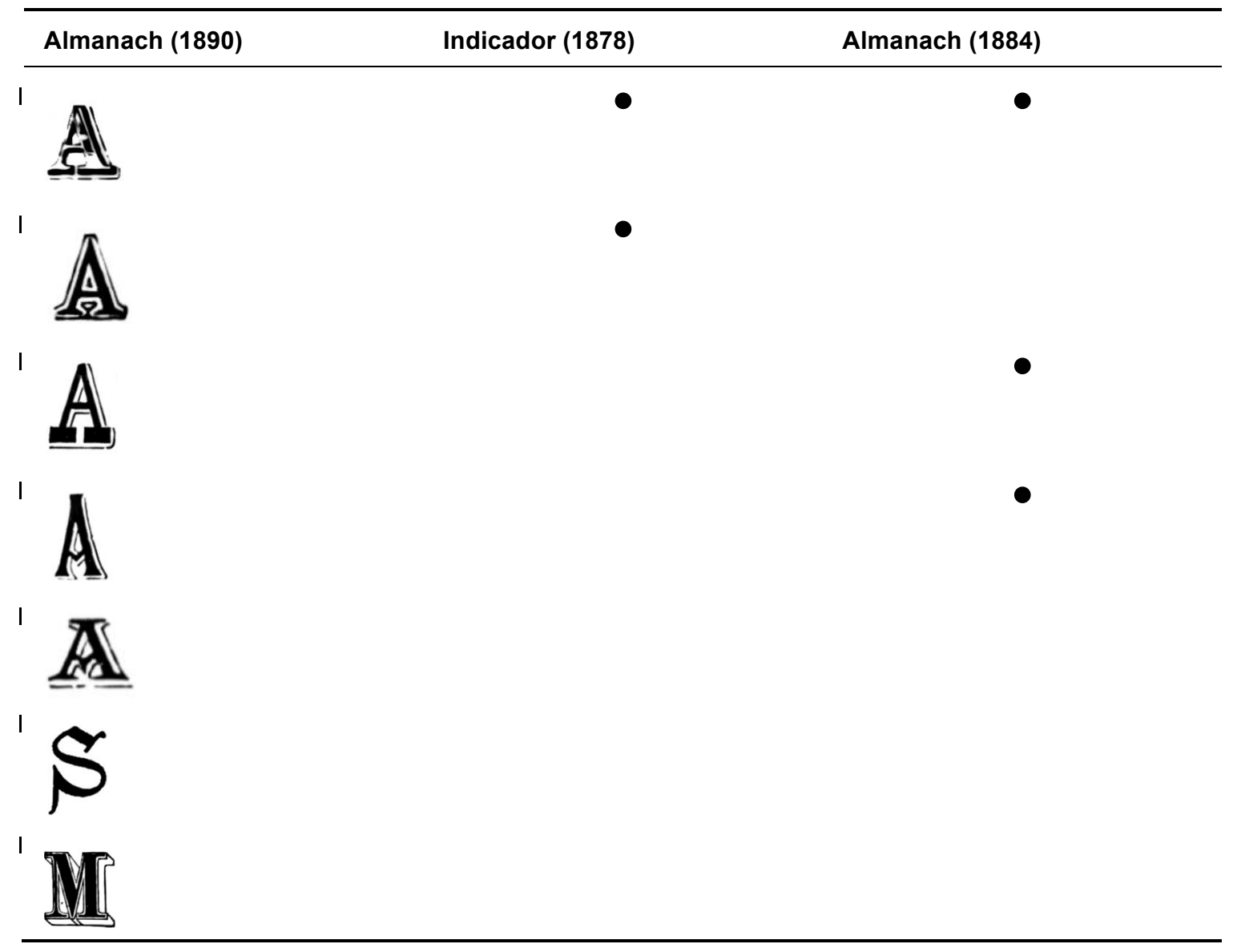


Tabela 4: Tipos serifados encontrados no Almanach Seckler para 1890 e sua ocorrência em publicações anteriores

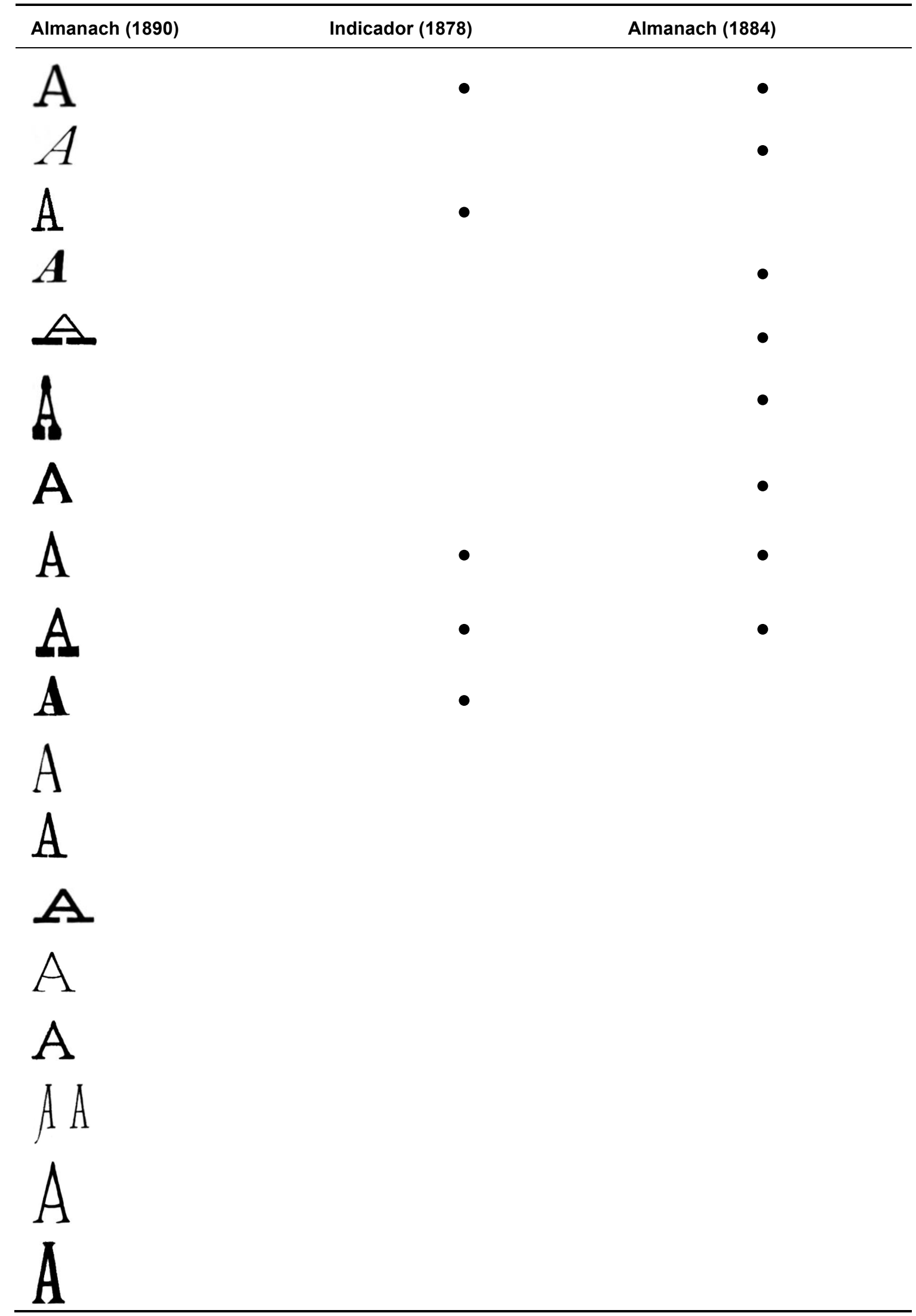




\section{Discussão}

Ao contrário da tendência observada por Oliveira e Farias (2018) no Indicador de 1878 e no Almanach Seckler para o ano de 1884, a maioria das fontes de título no Almanach Seckler para o ano de 1890, como pode ser observado nos resultados, são serifadas, seguidas por letras de fantasia, toscanas, escriturais e grotescas. Uma vez que fontes ornamentadas eram empregadas para chamar a atenção do leitor sem o uso de imagens (Farias, Aragão e Cunha Lima, 2012), esperava-se que, em situações como os anúncios de estabelecimentos comerciais e produtos analisados, fosse maior a variedade de tipos fantasia, escriturais e toscanos, ou que estes se repetissem com maior frequência do que as famílias serifadas e grotescas. A maior variedade e uso de serifadas pode estar relacionada com a disponibilidade de múltiplos tamanhos de corpo de uma mesma fonte - cerca de $90 \%$ das serifadas encontradas possuem pelo menos dois tamanhos de corpo distintos e duas também eram usadas para compor o corpo do texto -, tornando-as polivalentes. A tendência observada pode, também, indicar uma lenta transição entre a preferência por estilos ornamentados para formas mais simples.

A valorização da tridimensionalidade e profundidade em tipos toscanos constatada por Farias e Onoda (2015) pode ser observada também nas famílias de fantasia e escriturais encontradas no Almanach Seckler para o ano de 1890, revelando uma recorrência característica do gosto tipográfico local. Ademais, percebe-se a descontinuação do uso dos tipos góticos, que até 1884 eram maioria entre os tipos escriturais das oficinas de Seckler.

Em termos de novidades, na comparação dos resultados com as publicações de $1878 \mathrm{e}$ 1884 , a categoria que teve mais adições no período entre 1883 e 1889 foi a das serifadas (8 famílias), seguida pelos tipos de fantasia e escriturais ( 3 famílias cada) e grotescas ( 2 famílias), somando 16 novas famílias de fontes de título no total. Tal crescimento indica que o repertório tipográfico de Seckler continuou a se expandir significativamente após 1884, ainda que em um ritmo menor que o verificado entre 1878 e 1884, como observaram Oliveira e Farias (2018).

\section{Conclusão}

A análise de fontes de título presentes no Almanach do Estado de São Paulo para 1890 revela a predominância de fontes serifadas, reforçada pelo crescimento desse estilo no repertório de Seckler, e a valorização da tridimensionalidade em tipos toscanos, fantasia e escriturais como características relevantes do gosto tipográfico paulistano do final do século XIX.

Os resultados dessa pesquisa contribuíram significativamente para o trabalho de catalogação, análise e histórico do repertório tipográfico de Jorge Seckler e impulsiona investigações da memória gráfica oitocentista, assim como auxilia na expansão dos estudos sobre critérios para uso dos tipos pelos impressores. 


\section{Agradecimento}

A pesquisa relatada neste artigo inclui dados levantados pelas bolsistas de iniciação científica Heloísa Barbosa de Oliveira e Marina Ayumi Onoda, e foi realizada com apoio do CNPq.

\section{Referências}

Cruz, H. F. (2013). São Paulo em papel e tinta: periodismo e vida urbana 1890-1915. São Paulo: Arquivo Público do Estado de São Paulo.

Farias, P. L. (2016). Estudos sobre tipografia: letras, memória gráfica e paisagens tipográficas [Tese de Livre Docência em Design]. Faculdade de Arquitetura e Urbanismo, Universidade de São Paulo, Brasil. https://doi.org/10.11606/T.16.2017

Farias, P. L., Aragão, I. \& Lima, E. C. (2012). Unraveling aspects of Brazilian design history through the study of 19 th century almanacs and type specimens. Conference Proceedings: Design Research Society, 2, 498-511.

Farias, P. L., Lima, E. C. (2017). Transatlantic eccentricities: tuscan typefaces as an example of transnational typographic taste. Communication Design, 4, 4-20. http://dx.doi.org/10.1080/20557132.2016.1275452

Farias, P. L.; Onoda, M. A. (2015). Letras toscanas no repertório tipográfico de Jorge Seckler (1883-1895). Anais do Congresso Internacional de Design da Informação, 7, 883-892. https://doi.org/10.5151/designpro-CIDI2015-cidi_57

Oliveira, H. B. \& Farias, P. L. (2018). Memória Gráfica Paulistana: o repertório de tipos da oficina tipográfica de Jorge Seckler entre 1878 e 1884. Anais do Congresso Internacional de Design da Informação, 8, 1518-1523. https://doi.org/10.5151/cidi2017-147u

\section{Sobre as autoras}

Luiza M. Yoshimura, bolsista de Iniciação Científica, USP, Brasil <luizayoshimura@usp.br> Priscila L. Farias, Doutora, Professora Associada, USP, Brasil <prifarias@usp.br> 